\title{
Centroid Fault-Plane Inversion in Three-Dimensional Velocity Structure Using Strong-Motion Records
}

\author{
by Wei-An Chao, Li Zhao, and Yih-Min Wu
}

\begin{abstract}
The Chia-yi area in southwestern Taiwan is a region of relatively high seismicity. Frequent earthquakes of various magnitudes in the shallow crust provide valuable information for understanding the regional seismotectonic environment. In this study, we use strong-motion records from the 22 October 1999, $M_{\mathrm{L}} 6.4$ Chia-yi earthquake sequence to determine the focal mechanisms based on a criterion combining the $P$-wave polarity and the cross correlations between recorded and synthetic waveforms. A recent 3D structural model for the study region is used, and to ensure the computational efficiency, a database is established for the Green's functions obtained by the finite-difference method. Optimal focal depths and fault-plane solutions are obtained through a grid-search scheme driven by the genetic algorithm to further improve the efficiency. We apply this approach to determine the focal mechanisms and centroid depths of the small and moderate events in the Chia-yi earthquake sequence. Results show dominant strike-slip and thrust mechanisms that are in good agreement with previous results based upon $P$-wave first-motion polarities and moment-tensor inversions. This highly automatic and efficient approach will enable the determination of focal depths and fault-plane solutions immediately following the occurrence of small- to moderate-sized earthquakes.
\end{abstract}

\section{Introduction}

Taiwan is located at a plate boundary zone with complex tectonic structures and high seismicity. The determinations of frequently occurring regional earthquakes and their source parameters are important to the understanding of regional seismotectonics. In Taiwan, the Central Weather Bureau (CWB) monitors the regional earthquake activity by an array of densely deployed networks consisting of a variety of instruments, such as the Taiwan Strong-Motion Instrumentation Program (TSMIP, Liu et al., 1999) and CWB Seismic Network (CWBSN, Shin, 1993) composed of strong-motion, short-period, and broadband stations. The Institute of Earth Sciences (IES) of Academia Sinica operates the Broadband Array in Taiwan for Seismology (BATS) for a wide range of seismological research (Kao et al., 1998). These networks provide excellent seismic records for studying regional structure and earthquakes.

Since the inception of seismic networks in Taiwan in the early 1990s, a large quantity of records have been accumulated from frequently occurring earthquakes around Taiwan, which enabled numerous studies to be carried out on imaging the $3 \mathrm{D}$ changes of the regional crustal and uppermost mantle structures (e.g., Wu, 1978; Roecker et al., 1987; Rau and Wu, 1995; Ma et al., 1996; Kim et al., 2005; Wu et al., 2007; Wu, Chang, et al., 2009; Wu, Shyu, et al., 2009), relocation of earthquakes (e.g., Wu, Chang, et al., 2008), and earthquake focal-mechanism determination (e.g., Kao et al., 1998; Kao and Jian, 1999; Kao et al., 2002; Wu, Zhao, et al., 2008; Wu et al., 2010). These results have helped advance our understanding of both the seismic velocity structures and the tectonic environment beneath Taiwan.

In determining the focal mechanisms of regional earthquakes, the most widely adopted approach uses the polarities of $P$-wave first motions. However, because it requires a sufficient number of data points on the focal sphere to delineate the fault plane, focal-mechanism determination using firstmotion polarity is best suited for well-recorded events with good station coverage and signal-to-noise ratio (SNR). First-motion focal-mechanism determination is also prone to errors caused by uncertainties in the determination of firstmotion polarity due to either lateral heterogeneities or the earthquake source radiation pattern. As a result, most modern broadband networks have adopted a waveform-fitting approach in their routine inversions of source parameters of regional earthquakes. To date, waveform inversions for focal mechanisms are mostly based on Green's functions in regionally averaged 1D Earth models, which have proven to be effective for moderate earthquakes.

The use of 1D Green's functions may lead to two potential biases in the focal mechanism solutions. First, an incorrect structural model for the source region results in 
errors in the estimations of not only the source depths but also the take-off angles of seismic waves, which contribute to the errors in focal-mechanism solutions. Second, regionally averaged 1D models can be effective only in modeling waveforms of relatively long periods that are excited by earthquakes of moderate sizes $\left(M_{\mathrm{L}} 5.0\right.$ and greater). For events of smaller magnitudes, however, short-period waves are more dominant, and 1D models are no longer good enough.

In this study, we develop a new approach to determining the focal mechanisms of small and moderate earthquakes by combining three effective ingredients: an optimization criterion including both first-motion polarity and $P$-waveform fitting, Green's functions in 3D velocity models, and a grid search for source depth and focal mechanism based on the genetic algorithm (GA). The adoption of a realistic Earth model will minimize the biases in source parameters resulting from a simplified 1D structure, whereas the other two choices ensure the use of sufficient information and efficiency in the solutions of focal mechanisms.

\section{Strong-Motion Waveform Data}

We take several events of magnitude 3.5-5 in the Chiayi region in southwestern Taiwan as examples. These events belong to an earthquake sequence following the 22 October 1999 Chia-yi earthquake $\left(M_{\mathrm{L}}\right.$ 6.4). It is the largest inland earthquake in southwestern Taiwan since the $1999 M_{\mathrm{L}} 7.3$ Chi-Chi earthquake. Figure 1 shows the earthquake and station distributions. The relocated epicenter of the mainshock is at $23.496^{\circ} \mathrm{N}$ and $120.447^{\circ} \mathrm{E}$, with a focal depth of $17.7 \mathrm{~km}$ (Wu, Chang, et al., 2008). The focal mechanism for the mainshock has been reported by BATS and global CMT solu- tions (see Data and Resources) and the first-motion solution (Wu, Zhao, et al., 2008; Wu et al., 2010). All of them suggest a thrust mechanism with the fault plane most likely striking in the north-south direction. The finite fault modeling (Ma and $\mathrm{Wu}, 2001)$ and the distribution of relocated aftershock hypocenters (Wu, Chang, et al., 2008) indicated a westdipping fault plane. However, the slip direction and focal depth from the published source mechanisms for this earthquake are quite different, as shown by the focal mechanism symbols in Figure 1b. This discrepancy prompted us to further examine the focal mechanisms of moderate and small events in this earthquake sequence based on 3D Green's functions.

Among the events in the Chia-yi earthquake sequence, we selected 13 earthquakes in a one-month period following the main shock. These events were recorded by at least four TSMIP strong-motion stations with good SNR; the stations cover at least three quadrants around the focal sphere, and all of them are located within $40 \mathrm{~km}$ from the earthquakes. The TSMIP consists of over 800 free-field stations densely distributed throughout the Taiwan Island (Liu et al., 1999). Each TSMIP station is equipped with a force-balance accelerometer with a sampling rate of $200 \mathrm{~Hz}$ or higher. These earthquakes (excluding the mainshock) have local magnitudes $M_{\mathrm{L}}$ between 3.5 and 6.0 in the CWB earthquake catalog (see Data and Resources). In this study, we used the verticalcomponent acceleration seismograms. We first removed the mean and linear trend before the $P$-wave arrivals and then integrated the acceleration to obtain velocity waveforms for our analysis. Figure 2 displays examples of the original strong-motion accelerograms as well as the integrated velocities for the $M_{\mathrm{L}} 5.1$ event that occurred on 23 October 1999. These seismograms are all band-pass filtered (a)

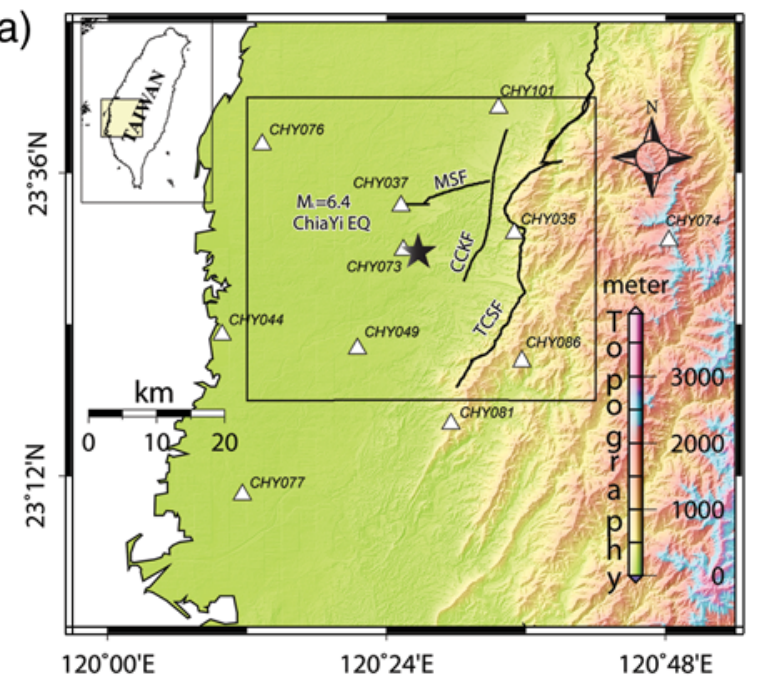

(b)

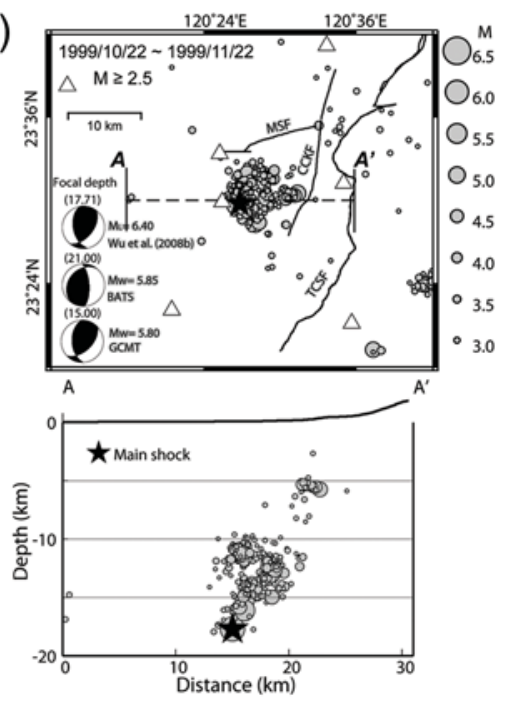

Figure 1. (a) Distribution of TSMIP stations shown by white triangles. Black star indicates the 22 October $1999, M_{\mathrm{L}} 6.4$ Chia-yi earthquake. Active faults published by the Central Geological Survey (CGS) of Taiwan are depicted by thick black lines. MSF: Meishan fault; CCKF: Chiuchiungkeng fault; TCSF: Tachienshan fault. (b) Distribution of relocated epicenters of $M \geq 2.5$ events in the Chia-yi earthquake sequence (Wu, Chang, et al., 2008). Three focal mechanisms for the mainshock are from the catalogs of Wu, Zhao, et al. (2008) and BATS and global CMT solutions. East-west profile shows source depth distribution along profile AA'. 
(a)
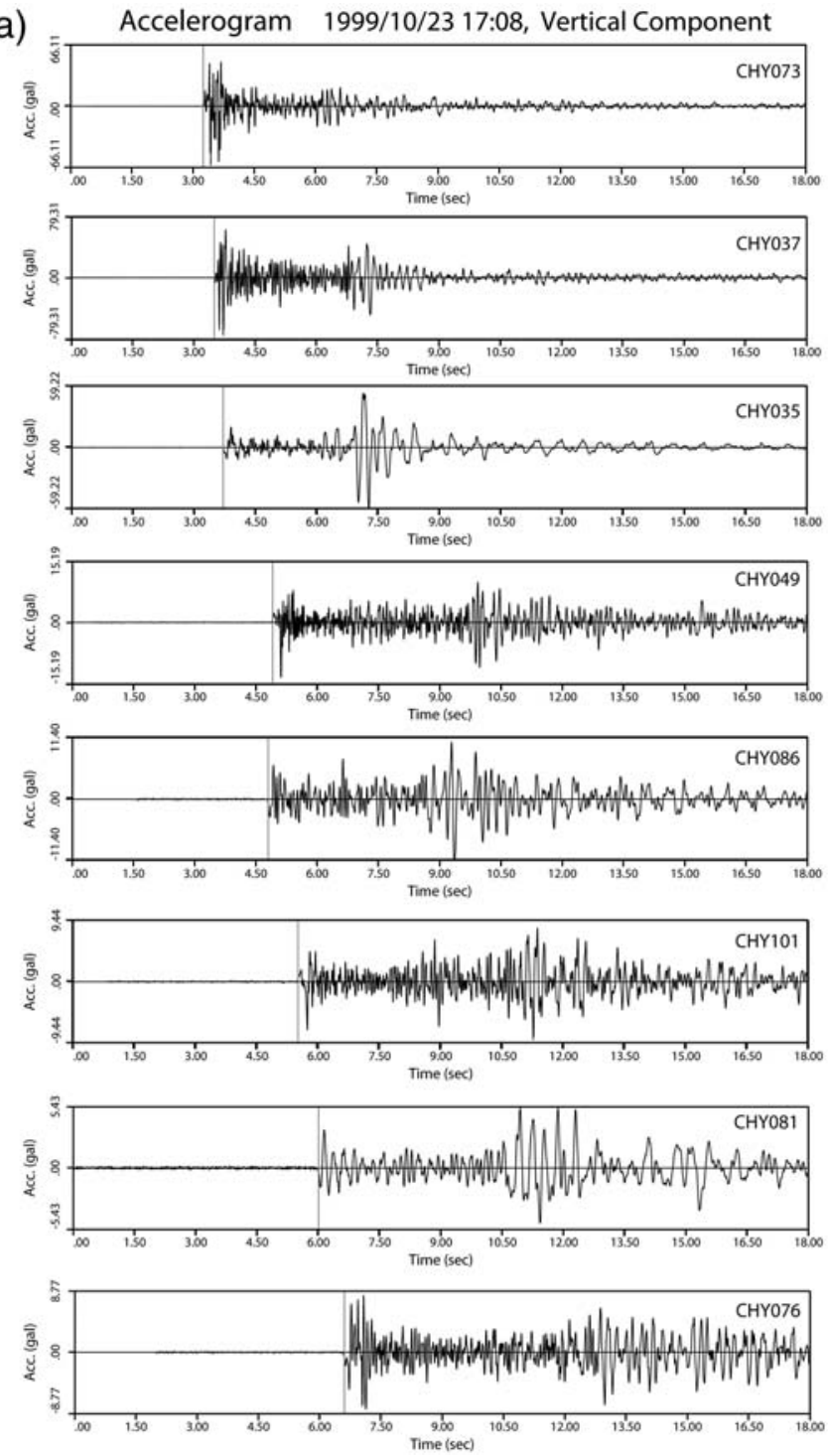

(b)
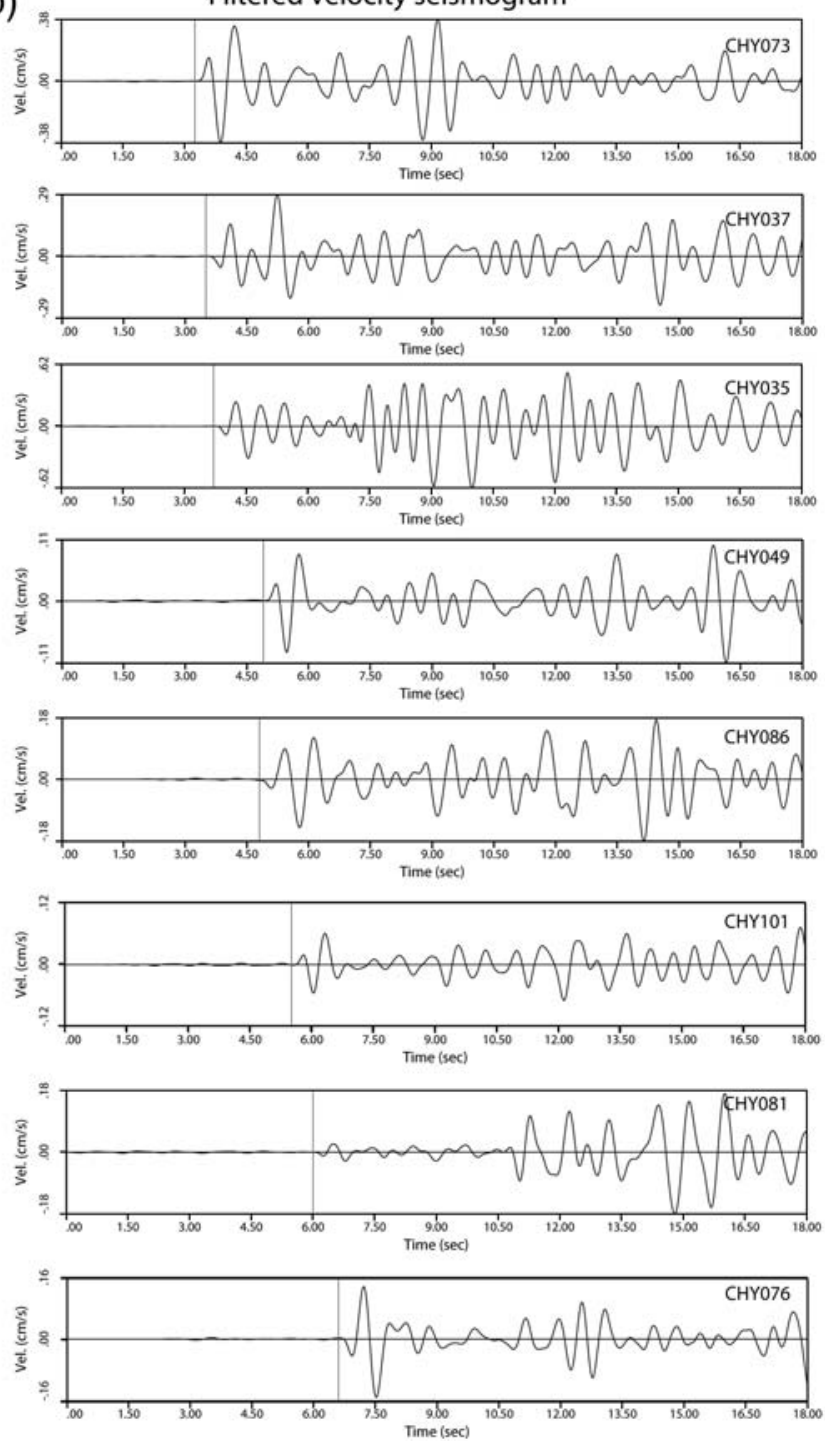

Figure 2. (a) Strong-motion accelerograms and (b) filtered velocity seismograms. The gray vertical lines indicate the time point of $P$ arrival determined by the autopicker.

by a fourth-order Butterworth filter with corner frequencies of $0.5 \mathrm{~Hz}$ and $2.0 \mathrm{~Hz}$. We used these cutoff frequencies only for the aftershocks in the Chia-yi sequence because those smaller earthquakes usually do not excite sufficient longperiod energy and thus their strong-motion records may have a relatively poor SNR in longer-period signals, especially for the smallest $M_{\mathrm{L}} 3.5$ event for which we used $0.8 \mathrm{~Hz}$ for the lower cutoff frequency. However, for the $M_{\mathrm{L}} 6.4$ mainshock, we use the cutoff frequencies of $0.3 \mathrm{~Hz}$ and $1.0 \mathrm{~Hz}$ in bandpass filtering of the seismograms.

\section{Focal Mechanism Solutions}

In this study, our focus is on the mechanisms of relatively small earthquakes. As a result, our working frequency band is also relatively high, between $0.5 \mathrm{~Hz}$ and $2 \mathrm{~Hz}$. A simple 1D average structure may not be accurate enough to predict waveforms at such frequency. In order to minimize the effect of lateral heterogeneities on waveform inversion, we use a recent 3D tomography model of Wu et al. (2007) and adopt the strain Green's tensor (SGT) approach (Zhao et al., 2006), in which we compute the 3D SGTs by a fourth-order staggered-grid finite-difference method (Olsen, 1994; Graves, 1996). With the SGT approach, we can store the SGTs on all grid points in a small volume surrounding the source region so as to ensure the efficiency in calculating synthetics and, in the meantime, keep the storage requirement low without sacrificing accuracy. In forward seismicwave simulations, an immediate linear relationship between the displacement and the six elements of a general moment tensor is provided by the six elements of the station SGT (Zhao et al., 2006) by virtue of the reciprocity theorem (Aki and Richards, 2002). 
Generally speaking, the take-off angle and receiver azimuth have a strong influence on the $P$-wave portion of the waveform; thus, in selecting stations we considered the azimuthal coverage of stations and the distribution of takeoff angles. Figure 1a shows the distribution of the 11 strongmotion stations selected for this study. An SGTs database was calculated for all these 11 stations. The finite-difference simulations were carried out in a volume of $80 \mathrm{~km} \times 106 \mathrm{~km}$ in horizontal dimension and from the surface down to a depth of $60 \mathrm{~km}$. These simulations provide accurate waveforms up to $2 \mathrm{~Hz}$. Table 1 summarizes the parameters related to the finite-difference simulations. With sampling intervals of $240 \mathrm{~m}$ in space and $0.03 \mathrm{~s}$ in time, the final SGT database for the 11 stations occupies about $138 \mathrm{~GB}$ of disk space. With this SGT database, 3D synthetic seismograms at the 11 stations from any event located in the source region can be computed by simply retrieving the appropriate SGTs from the database and applying the reciprocity theorem, with the same accuracy of a forward simulation but much higher efficiency. Figure 3 shows the comparison of the seismogram calculated by a forward finite-difference simulation with that calculated by reciprocity using the SGT database. The two different calculations yield exactly the same result.

In this study, we use both the polarity and the waveform of the $P$ wave in constraining the focal mechanisms. The $P$-wave arrivals are detected from the vertical-component accelerograms by an autopicker described by Allen (1978). Then we perform a waveform-fitting inversion using waveforms within a time window of variable length for each record. The length of the time window is roughly two full cycles after the arrival of the $P$ wave. These truncated time windows $\left(\mathrm{TTW}_{2}\right)$ were automatically calculated in the observed seismograms. Figure 4a displays an example of the $\mathrm{TTW}_{2}$ determination for a band-pass-filtered seismogram. The time window spans the duration from the autopicked $P$-wave arrival time to the fourth zero-crossing point on the seismogram. In the synthetic seismogram, the selected $P$ wave $\left(u_{s}\right)$ is obtained in the same way. The travel-time anomaly $(\delta t)$ is determined at the maximum of the crosscorrelation between the synthetic and recorded $P$ waves by an automatic picking scheme, with an allowance of $\pm 1 \mathrm{~s}$ time shifts to avoid the autopicking error (Fig. 4b). The maximum synthetic-record cross-correlation coefficient $C_{\mathrm{sr}}$ is

Table 1

Parameters in Finite-Difference Simulations

\begin{tabular}{lc}
\hline \multicolumn{1}{c}{ Parameter } & Value \\
\hline Model dimensions $\left(\mathrm{km}^{3}\right)$ & $80 \times 106 \times 60$ \\
Number of grid points & $2.35 \times 10^{9}$ \\
Grid spacing $(\mathrm{m})$ & 60 \\
Time step $(\mathrm{s})$ & 0.003 \\
Minimum $S$-wave velocity $(\mathrm{km} / \mathrm{s})$ & 0.6 \\
Propagation time $(\mathrm{s})$ & 30 \\
Maximum frequency resolution $(\mathrm{Hz})$ & 2 \\
Wall-clock time per simulation $(\mathrm{hr})$ & 31 \\
\hline
\end{tabular}

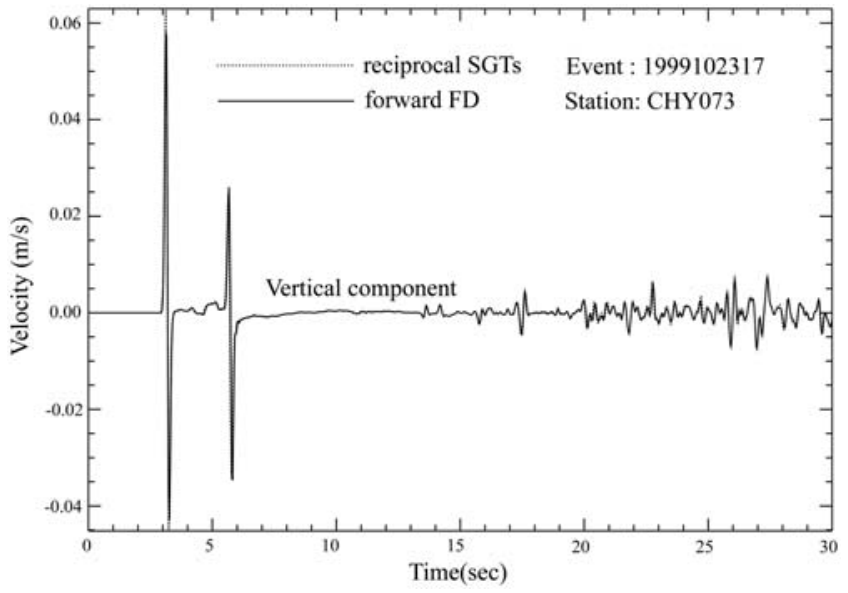

Figure 3. Comparison of the synthetic seismogram calculated by forward finite-difference calculation (solid line) with that obtained reciprocally using the SGT databases (dotted line).

normalized by the maximum autocorrelation coefficients $C_{s s}$ and $C_{r r}$ of the synthetic and recorded $P$ waves, respectively, as follows:

$$
N C C=\frac{C_{\mathrm{sr}}}{\sqrt{C_{s s} C_{r r}}}
$$

where $N C C$ is the normalized cross-correlation coefficient. The total cross-correlation coefficient is the average over all stations:

$$
\begin{aligned}
C_{c} & =\frac{1}{n_{s}} \sum_{n=1}^{n_{s}} N C C_{n} \\
& =\frac{1}{n_{s}}\left(N C C_{1}+N C C_{2}+\cdots+N C C_{n_{s}}\right),
\end{aligned}
$$

where $n_{s}$ is the number of stations for a given event. We also use the polarities of recorded and synthetic $P$ waves as additional information in the optimization process. Figure $4 \mathrm{~b}$ shows the example of a $P$-wave first-motion polarity coefficient $(P P C)$ determination. $P P C$ is 1 if the observed and synthetic $P$ waves have the same polarity or 0 otherwise. The total $P$-wave polarity coefficient is also an average over all stations:

$$
P=\frac{1}{n_{s}} \sum_{n=1}^{n_{s}} P P C_{n}
$$

Finally, we define a $P$-wave fitness criterion by a weighted coefficient $W C$ :

$$
W C=w_{c} \cdot C_{c}+w_{p} \cdot P,
$$

where $w_{c}$ and $w_{p}$ are weighting factors for $P$-waveform cross-correlation and polarity, respectively. We experimented with different values of the weighting factors, and we found that $w_{c}=0.3$ and $w_{p}=0.7$ lead to optimal fitting and stable mechanisms results.

For the optimization process, we perform the GA in a nonlinear global search for the best combination of the strike, 
(a)

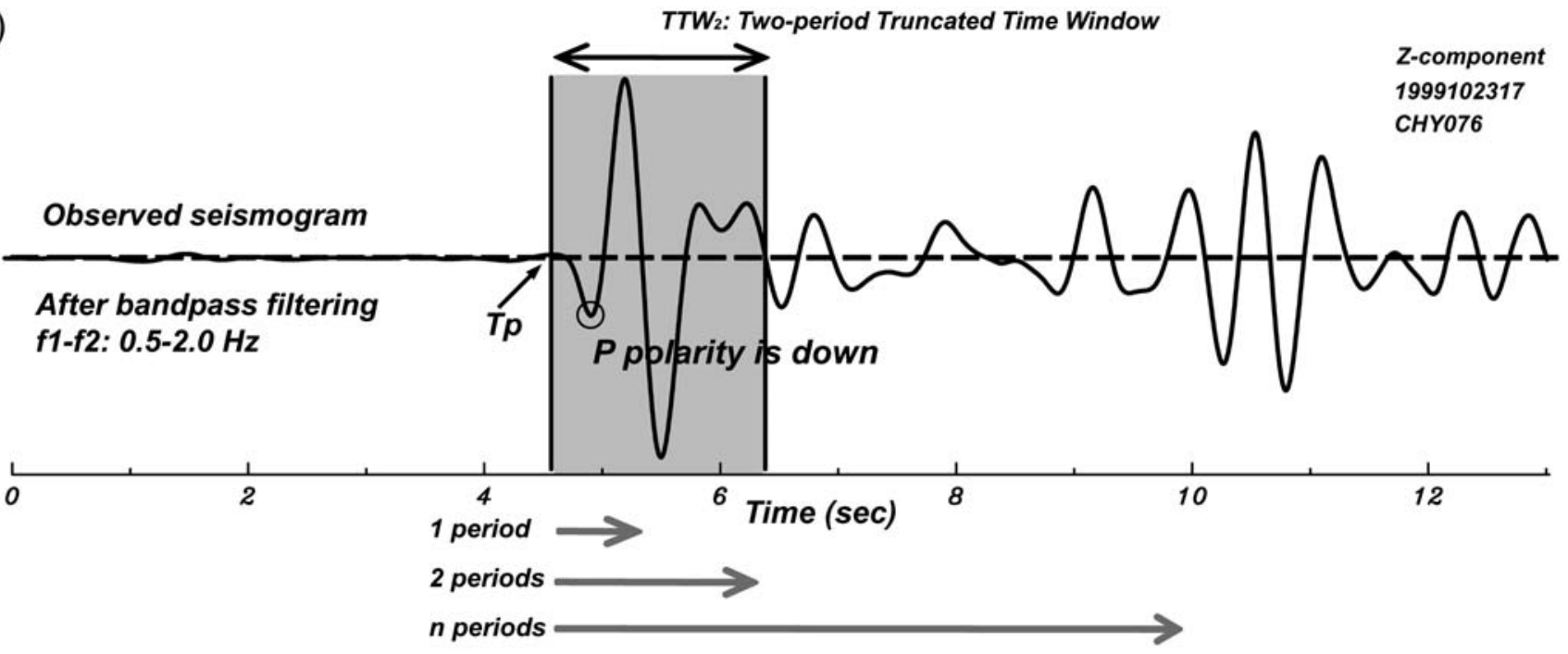

(b)

- Quantifying the difference between observed $\left(u_{r}\right)$ \& isolated synthetic $\left(u_{*}\right)$ seismogram. Full synthetic waveform

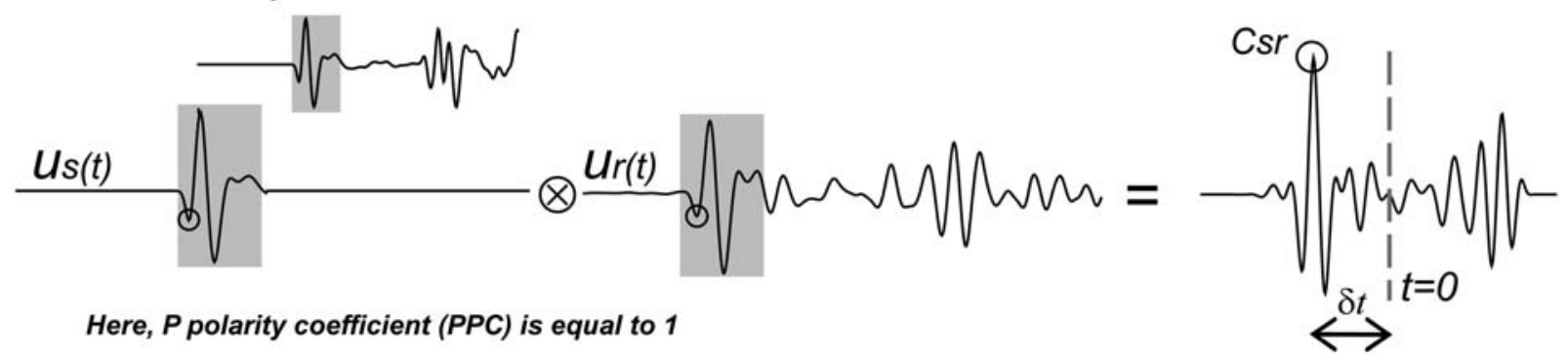

Figure 4. (a) Example of the automatic determination of the truncated time window of two full cycles $\left(\mathrm{TTW}_{2}\right)$ in the observed seismogram. An isolated $P$ wave is also obtained in the synthetic waveform. (b) Example of coefficient $C_{\mathrm{sr}}$ and $P P C$ determination. The time series in the lower right corner shows the cross correlagram between isolated $P$ waves in the synthetic and observed seismograms.

dip, and rake angles that provide the maximum weighted coefficient $W C$. The GA is an effective and efficient nonlinear optimization algorithm and has been widely used in seismology (e.g., Holland, 1975; Sambridge and Drijkoningen, 1992; Kobayashi and Nakanishi, 1994; Wu, Zhao, et al., 2008). For solving nonlinear optimization problems, the GA is a very powerful global searching tool in comparison to conventional methods, such as the grid search (Snoke et al., 1984; Snoke, 2003); iterative gradient search (Udias and Buforn, 1988) algorithms and can effectively avoid the trappings of local minima.

In our GA search of fault-plane solutions, 24 bits are used to represent the fault-plane parameters, with 9 bits for strike $\left(0^{\circ} \leq\right.$ strike $\left.\leq 360^{\circ}\right), 7$ bits for dip $\left(0^{\circ} \leq \operatorname{dip} \leq 90^{\circ}\right)$, and 8 bits for rake $\left(0^{\circ} \leq\right.$ rake $\left.\leq 180^{\circ}\right)$, to achieve a $1^{\circ}$ resolution. We set an initial condition of $1 \%$ reproduction rate, $49 \%$ for single-point crossover, 50\% mutation, and 6-bit reversal for each mutation in the optimization process.

In order to take the uncertainty in the earthquake source depth into account, we conduct the GA search of fault-plane solution for a number of source depths. We used the catalog of Wu, Chang, et al. (2008), in which the hypocenters of events have been carefully relocated by the 3D location method of Thurber and Eberhart-Phillips (1999). Then, in our focal mechanism determination, we performed the GA search for a number of source depths with a 2-km interval within a $\pm 5 \mathrm{~km}$ range around the depth values in the catalog of Wu, Chang, et al. (2008). The optimal focal depth is determined by the maximum of the parabolic curve fitting the maximum $W C$ value in the GA searches and the $W C$ values for the neighboring two depths. Examples of the source-depth determination are shown in Figure 5. To characterize the quality of the solution, we classify each result by assigning a letter (A-D) based on the $W C$ value.

After obtaining the optimal focal mechanism and depth, we estimate the seismic moment at the $n$th station using the maxima of the autocorrelations of the recorded and synthetic seismograms, $C_{r r}$ and $C_{s s}$, by the following formula:

$$
M_{0}^{n}=\bar{M}_{0}^{n} \cdot \sqrt{\frac{C_{r r}^{n}}{C_{s s}^{n}},}
$$

where $\bar{M}_{0}^{n}$ is the reference seismic moment used in numerical simulations to calculate the Green's functions. The moment 
(a)

No. 0
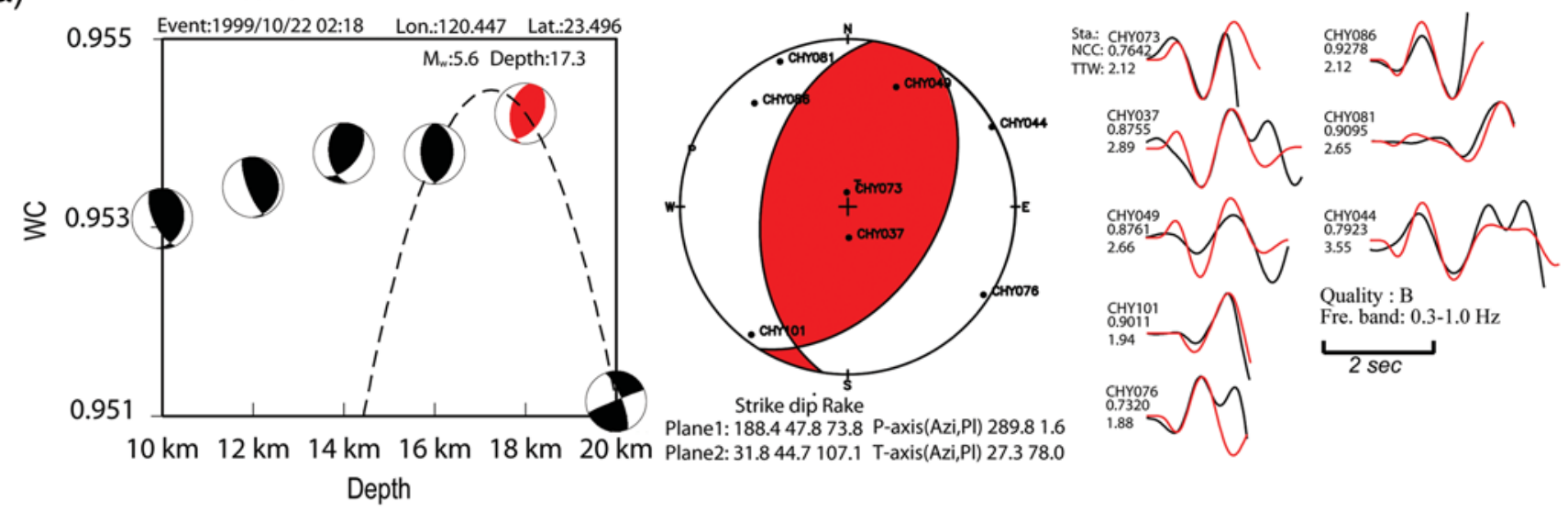

(b)
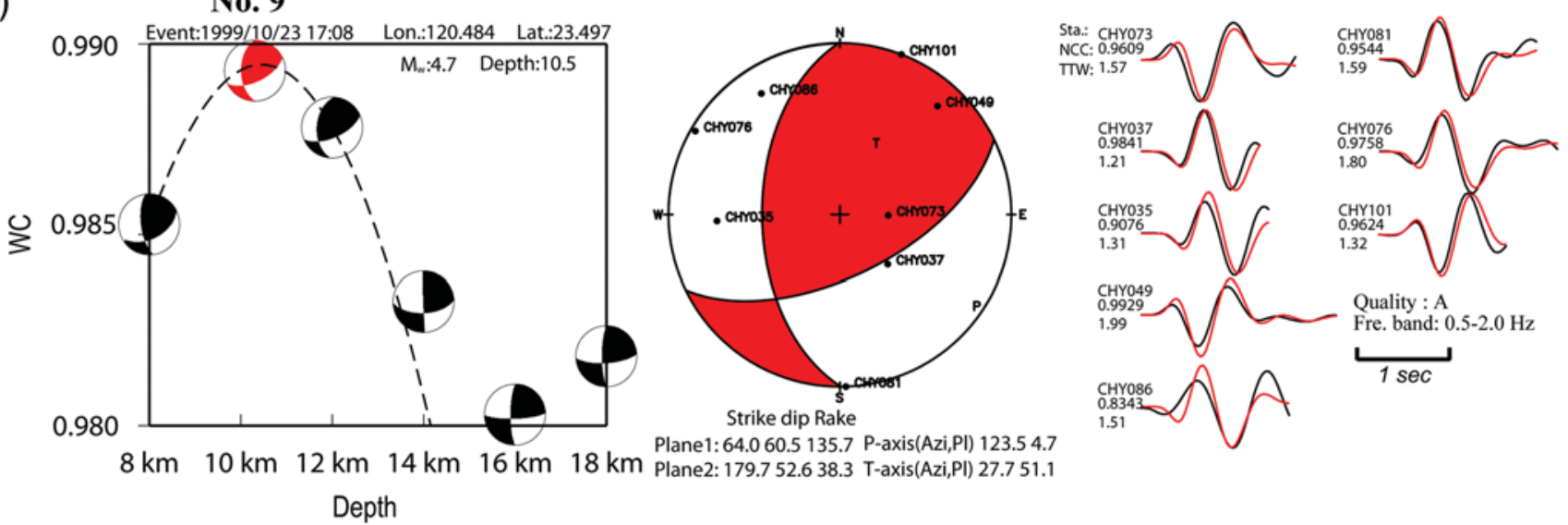

(c)
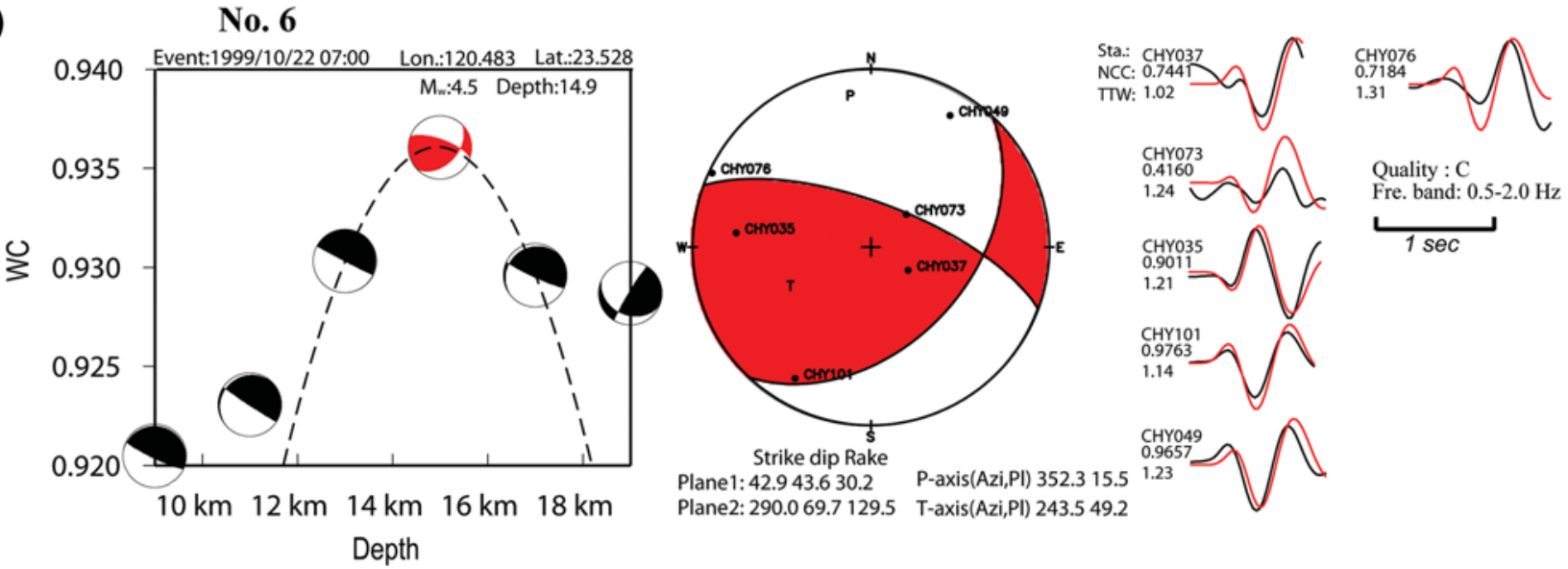
Plane1: 42.943 .630 .2 Plane2: 290.069 .7129 .5 T-axis(Azi,PI) 243.549 .2
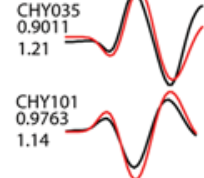

Depth

Figure 5. Results of waveform inversion for (a) the mainshock, (b) a moderate event, and (c) a smaller event. Left panels show the weighted coefficient $(W C)$ as a function of depth with different focal mechanism solutions. Focal mechanism symbols in red indicate the optimal solutions with maximum $W C$ values. The resulting fits between normalized synthetic (red traces) and observed (black traces) vertical seismograms for the optimal mechanisms are shown in the right panels. The station name, normalized cross-correlation coefficient (NCC), and truncated time window of two full cycles $\left(\mathrm{TTW}_{2}\right)$ are given beside the waveforms for each station.

magnitude $\left(M_{W}^{n}\right)$ can also be calculated (e.g., Kanamori, 1977)

$$
M_{W}^{n}=\left(\log M_{0}^{n}-16.1\right) / 1.5 .
$$

The final moment magnitude $\left(M_{W}\right)$ of the event is obtained from the average over all stations:

$$
M_{W}=\frac{1}{n_{s}} \sum_{n=1}^{n_{s}} M_{W}^{n}
$$

We have applied this approach to invert for the focal mechanisms of the Chia-yi earthquake sequence. The focal mechanism solutions as well as their relevant information for 


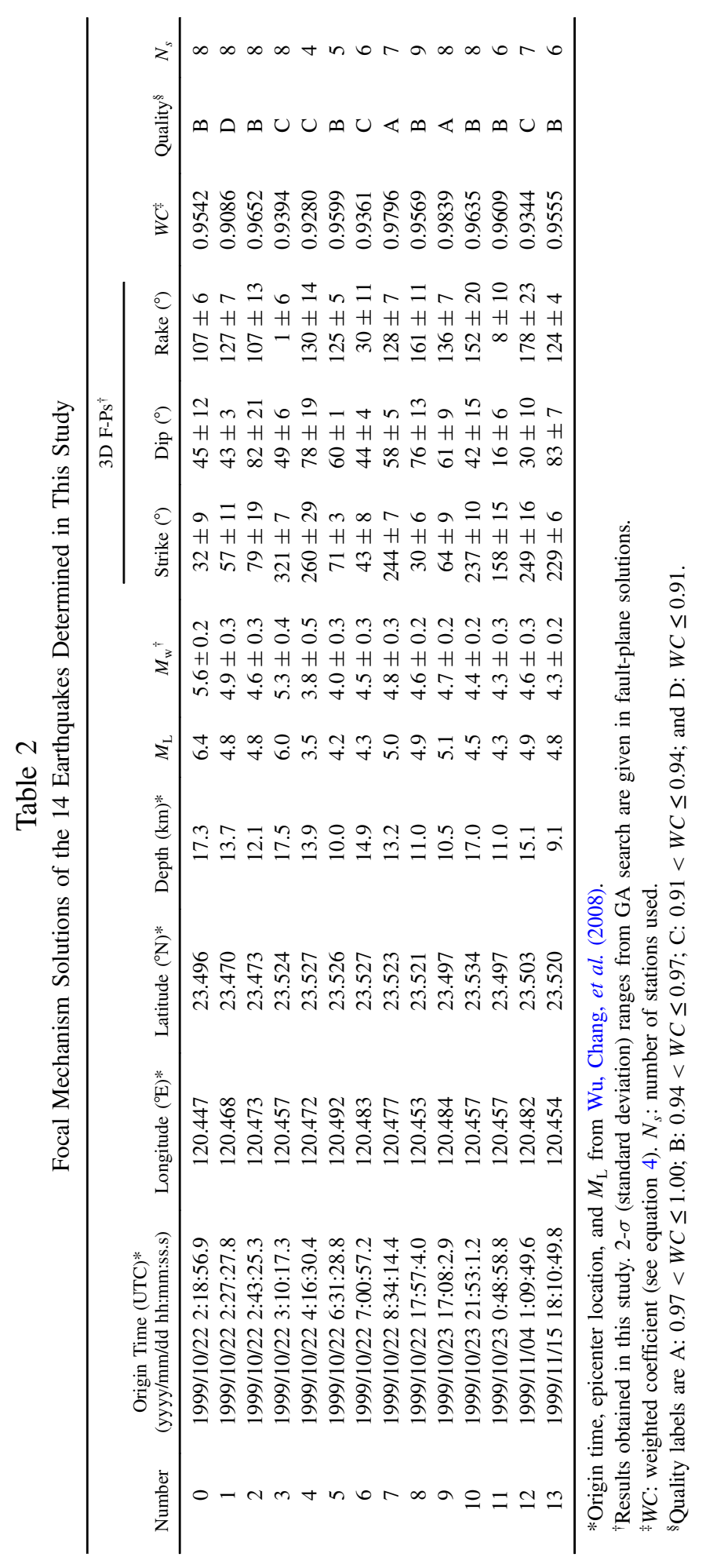


the 14 events in the Chia-yi earthquake sequence are listed in Table 2. Several examples are also presented in Figure 5. The synthetic waveforms match the observations generally well within the $\mathrm{TTW}_{2} P$-wave window, especially for event number 9, which yields excellent fit. In our result, the mainshock in the 1999 Chia-yi earthquake sequence occurred at $17.3 \mathrm{~km}$ depth, which is more consistent with the result in Wu, Chang, et al. (2008). Figure 6 also compares our results for the faultplane solutions of the 14 events with those in Wu, Zhao, et al. (2008) determined from first-motion polarization data, the BATS and global CMT solutions (see Data and Resources) obtained from long-period waveform inversion (Kao et al., 2002). It appears that our solutions with quality levels A and $\mathrm{B}$ are more consistent with both the result of $\mathrm{Wu}$, Zhao, et al. (2008) and the BATS CMT (see Data and Resources) solutions. The earthquakes in our study show either thrust or strike-slip mechanisms with mostly northwest-southeast trending $P$ axes (Fig. 6), in agreement with previous studies (Kao et al., 2002; Wu, Zhao, et al., 2008).

We have also conducted a series of experiments to investigate the influences of velocity structure, earthquake magnitude, and frequency band on focal mechanism inversion results. To study the structural effect, we obtained a 1D model by averaging the 3D structure in our study region and calculated its SGT database. Figure 7a displays the 1D and 3D synthetic waveforms at stations CHY035 and CHY073 from the $M_{\mathrm{L}} 3.5$ event (number 4 in Table 2). Compared with the 1D synthetics, 3D waveforms generally have stronger $P$-wave codas and different energy distributions inside the $P$-wave window. These discrepancies affect the inversion result

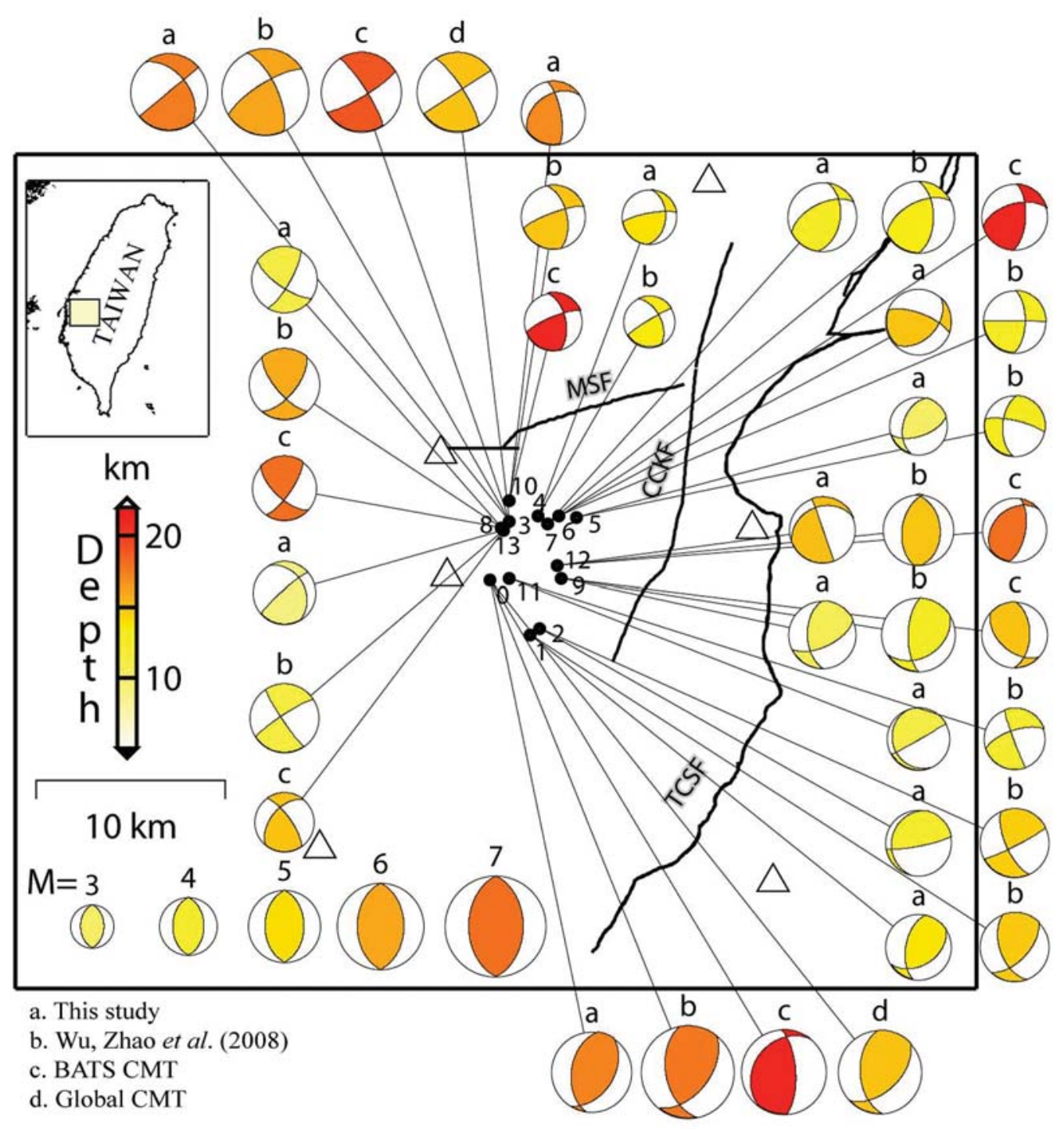

Figure 6. Comparison of focal mechanisms for 14 events determined in this study. For each event, up to four focal mechanisms are compared, including results from (a) this study, (b) F-P search (Wu, Zhao, et al., 2008), (c) BATS CMT, and (d) global CMT solutions. The sizes of the focal mechanism symbols are proportional to the magnitude, as shown by the symbols in the bottom left corner. Color indicates the focal depth. 
(a)
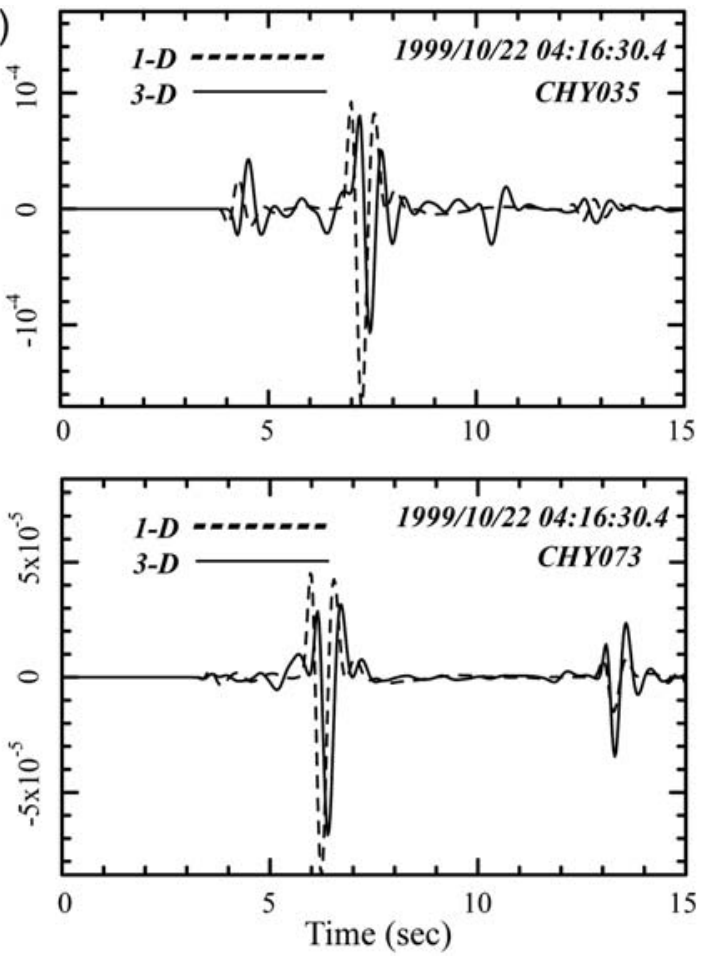

(b)

$\begin{array}{lll}0.3-1.0 ~ H z & 0.5-2.0 ~ H z & 0.8-2.0 ~ H z\end{array}$
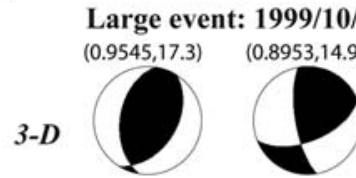

02:18:56.9

$(0.8262,17.9)$

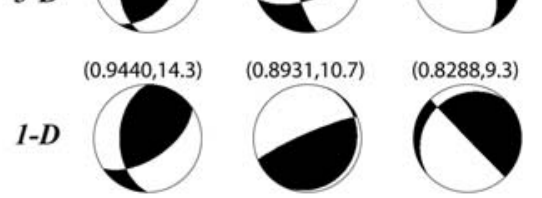

Small event: 1999/10/22 04:16:30.4

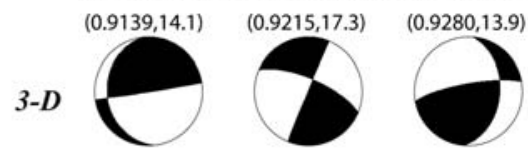

$1-D$

$(0.9197,10.8)$

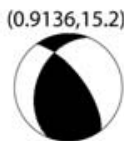

Recovery Test

$1-D$
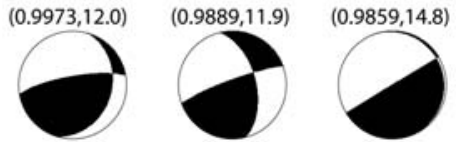

Figure 7. Experiments on focal mechanism inversion for large and small events (number $0\left[M_{\mathrm{L}} 6.4\right]$ and number $4\left[M_{\mathrm{L}} 3.5\right]$ ) using $1 \mathrm{D}$ and 3D models and different frequency bands. (a) Examples of 1D and 3D synthetic waveforms at stations $\mathrm{CHY} 035$ and $\mathrm{CHY} 073$ for the small event. (b) Focal mechanism results for large and small events using 3D and 1D models in three frequency bands. Given in the brackets above each focal mechanism symbol are the corresponding $W C$ value and the optimal focal depth. The last row shows results of a synthetic inversion test in which the 3D focal mechanism $(N C C=0.9280)$ is inverted using records from the 3D model and synthetics from the 1D model.

and can lead to more reliable focal mechanism results with an effective 3D model. For the effect of frequency band on focal-mechanism inversions, we have to consider two aspects. First, the smaller the magnitude, the higher the frequency of the $P$-wave signal radiated by the source will be. Therefore, reliable focal mechanisms are more likely obtained from longer-period signals for larger events and from shorter-period signals for smaller events. Second, 3D structural effect is usually stronger at shorter periods; thus, an average 1D model can sometimes be a reasonably good approximation to the 3D structure for longer-period signals. These analyses can be seen from the inversion experiments shown in Figure $7 \mathrm{~b}$ for a larger $M_{\mathrm{L}} 6.4$ event (number 0 in Table 2) and a smaller $M_{\mathrm{L}} 3.5$ event (number 4 in Table 2). For both events, the 3D model leads to the best focal mechanism solutions (judging by the $N C C$ values), with optimal solutions occurring at longer periods for the larger event and at shorter periods for the smaller event. With the 1D model, a good solution can be achieved for a larger event at longer periods because of a reasonably effective 1D model and sufficient radiation of $P$-wave energy, whereas for a small event, the optimal solution may be obtained in the middle-period band because of a smaller $P$-wave radiation at longer periods and an ineffective 1D model at shorter periods. This analysis is confirmed in a recovery test shown in Figure $7 \mathrm{~b}$ using the focal mechanism of event number 4 $\left(M_{\mathrm{L}} 3.5\right)$ in Table 2 or the focal mechanism symbol (a) of event number 4 in Figure 6.

\section{Discussion and Conclusions}

In this study, we have developed a highly automatic and efficient procedure to determine the focal mechanisms of small and moderate earthquakes in 3D structures. Considering the point-source mechanisms, we used longerperiod waves $(0.3-1.0 \mathrm{~Hz})$ for the mainshock in the Chia-yi earthquake sequence, a shorter-period band $(0.5-2.0 \mathrm{~Hz})$ for the smaller aftershocks. For the smallest, $M_{\mathrm{L}} 3.5$, event in this study, we used an even higher-frequency band $(0.8$ $2.0 \mathrm{~Hz}$ ) due to particularly low SNR below $0.8 \mathrm{~Hz}$. Generally, the strong-motion records may have relatively poor SNRs at long periods for smaller events. Some of the events studied here have relatively small $W C$ values due to poor SNRs. Moreover, relatively short $\mathrm{TTW}_{2}$ generally indicates that the record may be close to the nodal plane with vanishing amplitude. Inversion experiments of large and small events using 1D and 3D models as well as different frequency bands also demonstrate that for small earthquakes it is necessary to use higher-frequency signals and 3D structural models to obtained reliable focal mechanism solutions. 
Based on the source-depth values obtained from our study, it can be seen clearly that the earthquakes are mostly located between $9-\mathrm{km}$ and $18-\mathrm{km}$ depths, as shown in Figure 8 . The hypocenters of these events are located along a west-dipping trend with a dominant thrust component, extending upward from around the depth of $17 \mathrm{~km}$ (Fig. 8b). Chen et al. (2008) suggested that there are two faults delineated by seismicity distribution with backthrust and strike-slip faulting mechanisms. The right-lateral Meishan strike-slip fault, located at the northern margin of our study region, acts as a tearing fault (Shyu et al., 2005). According to our results for the focal mechanisms and hypocentral depths shown in Figure 8, the west-dipping trend of the fault is consistent with a dominant backthrust. However, event numbers $3,4,6,7,8,10$, and 13 suggest significantly different mechanisms, and their epicentral locations are at the northern end of our study area. In particular, event number 3 has a dominant right-lateral strike-slip component. There are two detachments under the coastal plain in southwestern Taiwan inferred from background seismicity (Chen et al.,

(a)
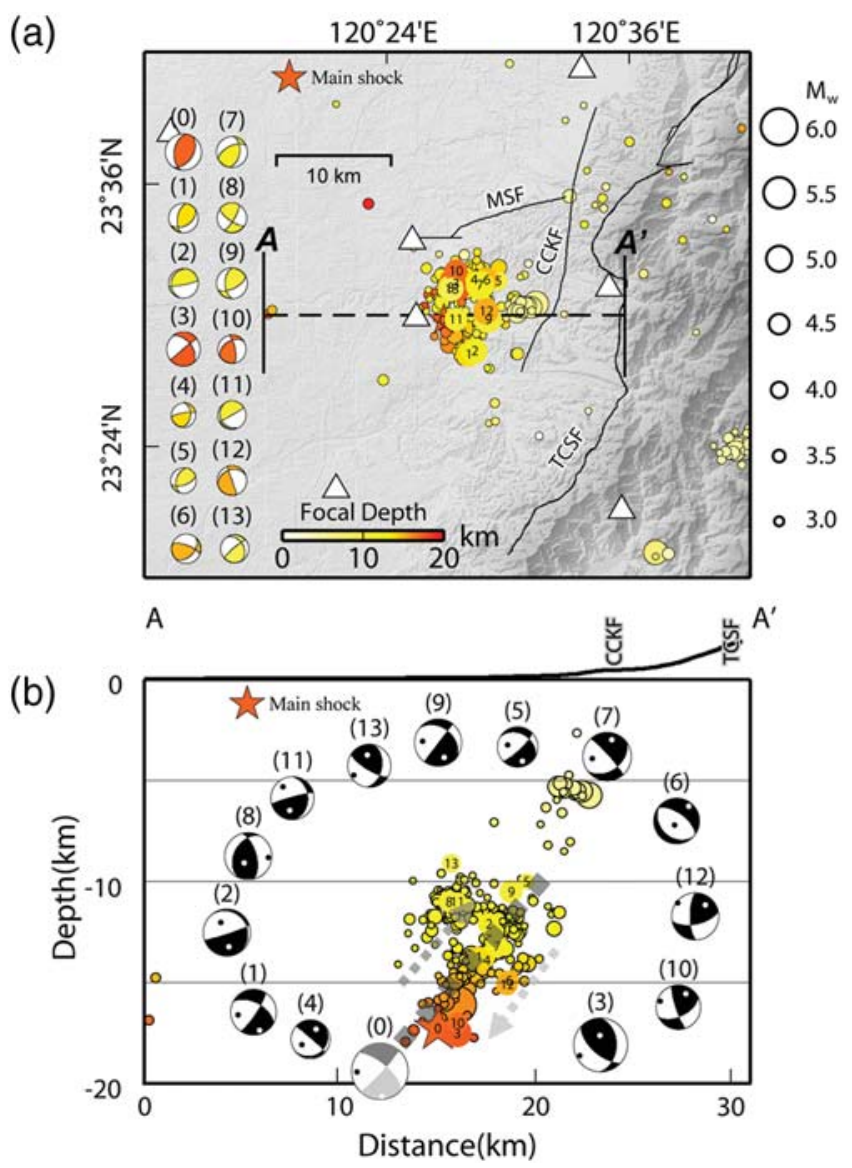

Figure 8. (a) Distribution of hypocenters from the catalog of $\mathrm{Wu}$, Chang, et al. (2008). The star indicates the hypocenter of the Chia-yi earthquake; the focal mechanism symbols show results from this study. The sizes of the symbols are proportional to the magnitude. (b) Depth distribution of hypocenters and focal mechanism solutions obtained in this study along the vertical profile $\mathrm{AA}^{\prime}$. Gray dashed line indicates the possible fault geometry.
2008). The focal mechanisms of event numbers 2,11 , and 8 may be interpreted as left-lateral strike-slip events occurring on the planes with lower and higher dip angles, respectively. Perhaps associated with the lower detachment (around 12-km depth, Chen et al., 2008).

The new approach developed in this study not only achieves efficiency with a high degree of automation in determining focal mechanisms in 3D structures, it also relaxes the demands for station coverage owing to the combination of waveform cross correlation and $P$-wave polarity used in GA searches. In most cases, records from only five stations are sufficient for reaching a reliable solution. Total amount of time required to obtain a solution is proportional to the number of trial source depths, a scenario suitable for parallelization. Therefore, this approach provides a means to automatically, reliably, and quickly determine the fault-plane solutions of small and moderate earthquakes in 3D models.

\section{Data and Resources}

Strong-motion waveform records used in this study are obtained from the Taiwan Strong Motion Instrumentation Program (TSMIP), a network managed by the Central Weather Bureau (CWB) of Taiwan. All TSMIP records are open to the public and can be obtained upon request from CWB. The earthquake catalog maintained by the CWB can be accessed at http://www.cwb.gov.tw/eng/seismic/seismic.htm (last accessed March 2011). The relocated earthquake catalog used in this study originated from Wu, Chang, et al. (2008). However, this catalog is routinely updated with new events added and existing ones revised using newly available data. The current catalog includes events between 1991 and 2007 and can be obtained upon request from Y.-M. Wu. BATS CMT solutions are available at http://bats.earth.sinica.edu.tw, and Global CMT solutions are maintained at http://www .globalcmt.org. Finite-difference simulations were carried out on the clusters at the National Center for High-performance Computing (NCHC) of Taiwan and at IES, Academia Sinica. The software package Generic Mapping Tools (GMT) (Wessel and Smith, 1998) was used in making some of the figures in this article.

\section{Acknowledgments}

The authors wish to thank Sean Ford and an anonymous reviewer for their constructive comments that helped improve the manuscript. This research has been supported by the Central Weather Bureau and the National Science Council of the Republic of China.

\section{References}

Aki, K., and P. G. Richards (2002). Quantitative Seismology, Second Ed., University Science Books, Sausalito, California, 700 pp.

Allen, R. V. (1978). Automatic earthquake recognition and timing from single traces, Bull. Seismol. Soc. Am. 68, 1521-1532.

Chen, Y. G., Y. T. Kuo, Y. M. Wu, H. L. Chen, C. H. Chang, R. Y. Chen, P. W. Lo, K. E. Ching, and J. C. Lee (2008). New seismogenic source and deep structures revealed by the 1999 Chia-yi earthquake sequence in southwestern Taiwan, Geophys. J. Int. 172, 1049-1054. 
Graves, R. W. (1996). Simulating seismic wave propagation in 3D elastic media using staggered-grid finite differences, Bull. Seismol. Soc. Am. 86, 1091-1106.

Holland, J. H. (1975). Adaptation in the Natural and Artificial Systems, University of Michigan Press, Ann Arbor, Michigan.

Kanamori, H. (1977). The energy release in great earthquakes, J. Geophys. Res. 82, 2981-2987.

Kao, H., and P. R. Jian (1999). Source parameters of regional earthquakes in Taiwan: July 1995-December 1996, Terr. Atmos. Ocean. Sci. 10, 585-604.

Kao, H., P. R. Jian, K. F. Ma, B. S. Huang, and C. C. Liu (1998), Moment-tensor inversion for offshore earthquakes east of Taiwan and their implications to regional collision, Geophys. Res. Lett. 25, 3619-3622.

Kao, H., Y. H. Liu, W. T. Liang, and W. P. Chen (2002). Source parameters of regional earthquakes in Taiwan: 1999-2000 including the Chi-chi earthquake sequence, Terr. Atmos. Ocean. Sci. 3, 279-298.

Kim, K. H., J. M. Chiu, J. Pujol, K. C. Chen, B. S. Huang, Y. H. Yeh, and P. Shen (2005). Three-dimensional $V_{P}$ and $V_{S}$ structural model associated with the active subduction and collision tectonics in the Taiwan region, Geophys. J. Int. 162, 204-220.

Kobayashi, R., and I. Nakanishi (1994). Application of genetic algorithms to focal mechanism determination, Geophys. Res. Lett. 21, 729-732.

Liu, K. S., T. C. Shin, and Y. B. Tsai (1999). A free-field strong motion network in Taiwan: TSMIP, Terr. Atmos. Ocean. Sci. 10, 377-396.

Ma, K. F., and S. I. Wu (2001). Quick slip distribution determination of moderate to large inland earthquakes using near-source strong motion waveforms, Earthq. Eng. Eng. Seismol. 3, 1-10.

Ma, K. F., J. H. Wang, and D. Zhao (1996). Three-dimensional seismic velocity structure of the crust and uppermost mantle beneath Taiwan, J. Phys. Earth 44, 85-105.

Olsen, K. B. (1994). Simulation of three-dimensional wave propagation in the Salt Lake Basin, Ph.D. Thesis, University of Utah, Salt Lake City, Utah, $157 \mathrm{pp}$.

Rau, R. J., and F. T. Wu (1995). Tomographic imaging of lithospheric structures under Taiwan, Earth Planet. Sci. Lett. 133, 517-532.

Roecker, S. W., Y. H. Yen, and Y. B. Tsai (1987). Three-Dimensional $P$ and $S$ velocity structures beneath Taiwan: Deep structure beneath an arc-continent collision, J. Geophys. Res. 92, 10,547-10,570.

Sambridge, M., and G. Drijkoningen (1992). Genetic algorithm in seismic waveform inversion, Geophys. J. Int. 109, 323-342.

Shin, T. C. (1993). The calculation of local magnitude from the simulated Wood-Anderson seismograms of the short-period seismograms in the Taiwan area, Terr. Atmos. Ocean. Sci. 4, 155-170.

Shyu, J. B. H., K. Sieh, Y. G. Chen, and C. S. Liu (2005). The neotectonic architecture of Taiwan and its implications for future large earthquakes, J. Geophys. Res. 110, B08402, doi 10.1029/2004JB003251.

Snoke, J. A. (2003). FOCMEC: FOCal MEChanism determinations, in International Handbook of Earthquake and Engineering Seismology, W. H. K. Lee, H. Kanamori, P. C. Jennings, and C. Kisslinger (Editors), Academic Press, San Diego, California, Ch. 85.12.

Snoke, J. A., J. W. Munsey, A. C. Teague, and G. A. Bollinger (1984). A program for focal mechanism determination by combined use of polarity and SV-P amplitude ratio data, Earthquake Notes 55, 15 pp.
Thurber, C., and D. Eberhart-Phillips (1999). Local earthquake tomography with flexible gridding, Comput. Geosci. 25, 809-818.

Udias, A., and E. Buforn (1988). Single and joint fault-plane solutions from first-motion datam, in Seismol. Algorithms, D. J. Doornbos (Editor), Academic Press, New York, 443-453.

Wessel, P., and W. H. F. Smith (1998). New, improved version of Generic Mapping Tools released, Eos Trans. AGU 79, 579.

Wu, F. T. (1978). Recent tectonics of Taiwan, J. Phys. Earth, S265-S299, 26 Suppl.

Wu, Y. M., C. H. Chang, L. Zhao, J. B. H. Shyu, Y. G. Chen, K. Sieh, and J. P. Avouac (2007). Seismic tomography of Taiwan: Improved constraints from a dense network of strong-motion stations. J. Geophys. Res. 112, B08312.

Wu, Y.-M., C. H. Chang, L. Zhao, T.-L. Teng, and M. Nakamura (2008). A. comprehensive relocation of earthquakes in Taiwan from 1991 to 2005, Bull. Seismol. Soc. Am. 98, 1471-1481, doi 10.1785/ 0120070166.

Wu, Y. M., C. H. Chang, L. Zhao, N. C. Hsiao, Y. G. Chen, and S. K. Hsu (2009). Relocation of the 2006 Pingtung earthquake sequence and seismotectonics in Southern Taiwan, Tectonophysics 479, 19-27, doi 10.1016/j.tecto.2008.12.001.

Wu, Y. M., Y. J. Hsu, C. H. Chang, L. S. Teng, and M. Nakamura (2010) Temporal and spatial variation of stress field in Taiwan from 1991 to 2007: Insights from comprehensive first motion focal mechanism catalog, Earth Planet. Sci. Lett. 298, 306-316, doi 10.1016/ j.eps1.2010.07.047.

Wu, Y. M., J. B. H. Shyu, C. H. Chang, L. Zhao, M. Nakamura, and S. K. Hsu (2009). Improved seismic tomography offshore northeastern Taiwan: Implications for subduction and collision processes between Taiwan and the southernmost Ryukyu, Geophys. J. Int. 178, 10421054.

Wu, Y. M., L. Zhao, C. H. Chang, and Y. J. Hsu (2008). Focal mechanism determination in Taiwan by genetic algorithm, Bull. Seismol. Soc. Am. 98, 651-661.

Zhao, L., P. Chen, and T. H. Jordan (2006). Strain Green's tensors, reciprocity and their applications to seismic source and structure studies. Bull. Seismol. Soc. Am. 96, 1753-1763.

Department of Geosciences

National Taiwan University

1 Roosevelt Road, Sec. 4

Taipei 10617, Taiwan

zhaol@earth.sinica.edu.tw

(W.-A.C., Y.-M.W.)

Institute of Earth Sciences

Academia Sinica

128 Academia Road, Sec. 2

Taipei 115 Taiwan

(L.Z.)

Manuscript received 10 September 2010 